\title{
Assessing the diversification of energy mix with the methods of entropy and hierarchy of information
}

\author{
Iliyan Petrov ${ }^{1}$ \\ ${ }^{1}$ Bulgarian Academy of Sciences, Institute of Information and Communication \\ Technologies, Dep. "Information Processes and Decision Support Systems", akad. Georgi \\ Bonchev srt., bl. 2, 1113 Sofia, Bulgaria
}

\begin{abstract}
Energy systems are a typical example of complex and dynamic systems and the study of their structure is of particular interest in theoretical and practical terms. Becoming the main trend of diversification and, renewable energies play important role in the evolution and dynamics of energy balances at the international, national, and local levels. Usually, natural sciences use Information Theory and the concept of entropy to assess diversity, uncertainty, and chaos in systems with a high number of components. An alternative approach to assess system complexity is to consider these issues from point of view of the concentration of resources, dominance, and hierarchy in the interactions between system components. This report presents an original method developed by the author for assessing the hierarchy in energy mix structures and the role of renewable energies. The author's studies in the field of energy explore the evolution of markets and energy balances (energy mixes) on an international, regional and national level with a special focus on the European Union and Bulgaria. The hierarchy approach provides results in a more logical, objective, and balanced format and improves the analysis in terms of energy security and diversification. In this paper, is presented a research on the structure of the energy mix in Bulgaria.
\end{abstract}

\section{Introduction}

Assessing the complexity and interactions in dynamical systems is a challenging process that requires logically defined methods and tools. Traditionally, as a first step (Level 1) in this process, the primary data for relative weights or probabilities (p) of the individual system's components are processed with some basic transformation function in terms of two alternative concepts: entropy $e(p)$ as a representation of diversity and uncertainty, and, hierarchy $h(p)$ - in the context of order, security, and domination. As a second step (Level2 ), the transformed output results from Level-1 for all individual components are summed to

\footnotetext{
*Corresponding author: petrovindex@gmail.com
} 
obtain an aggregation characterizing the complexity of the system as a whole. In symmetrical configurations, the parts " $p$ " of all " $n$ " components are equal $\left(\sum_{i=1}^{n} \frac{1}{n}=1\right)$, and, in these cases, the entropy of the system is maximal and the hierarchy is minimal. To individualize the various indicators or models, we use the first letter of the author's surname, placing it as an index to the symbol for entropy or hierarchy: "SE" - for "Shannon's Entropy" [1]; "RE" for Reni's Entropy" [2]; "HC" - for " Herfindahl Concentration (Hierarchy)" [3, 4], "PH" for " Petrov Hierarchy".

The summarized results at the macro level for all system configurations and distributions of relative weights can be classified in the Harrington's scale for psychophysical classification. This scale contains 6 phases and is a more detailed version of the traditional scale proposed by E. Harrington [5], which in its original form contains three or five classification intervals (0-0.2-0.37-0.63-0.8-1). Table 1 presents the 6 levels of structural space assessment in the Harrington-Petrov scale.

Table 1. Petrov Hierarchy in Harrington's assessment and classification scale

\begin{tabular}{|c|c|c|}
\hline Hierarchy labels & Quantitative scale & Qualitative scale \\
\hline Concentrated oligopoly (Mono-Duo-Tripoly) & $0.80-1.00$ & Extremely high \\
\hline Classic oligopoly & $0.63-0.80$ & Very high \\
\hline Enlarged Oligopoly & $0.50-0.63$ & Higher than average \\
\hline Polipoly & $0.37-0.50$ & Lower than average \\
\hline Multipoly & $0.20-0.37$ & Very low \\
\hline Hyperpoly & $0.00-0.20$ & Extremely high \\
\hline
\end{tabular}

The combination of quantitative and psycho-physical assessments improves information perception and shows the opposite concepts of the two approaches and the relationship between them. When we measure hierarchy we get an indirect idea of entropy: i.e., high hierarchy means low entropy and vice versa.

\section{Novel approach to Hierarchy as a complement to Entropy}

To improve the methods and tools for measuring the system complexity, we offer an original approach to assessing order and security, called "Petrov Logistic function Hierarchy $(P L H)$ ". The basic function for transforming empirical data for component's parts is defined as follows:

$$
p l h=\frac{i}{1+\left(\frac{\sum_{j=1}^{J} \log _{R_{j}} p_{i}}{J}\right)^{c}}
$$

where: $p l h$ - individual hierarchy at micro-level; $p_{i}$ - component's part (relative weight or probability); $p_{i}[0,1] ; R j$ - "reference (etalon) weight" or "Reference Structural Thresholds (RST) “; Rj $[0,1] ; J$ - number of $R j ; c$ - power factor, modelling the nonlinearly the structural interaction, c $[0,1]$. We experimented with different values for "Rj", "J" and „c" for optimizing the basic function in equation (1). In a combination of $\left(J=2 ; R_{1}=0.001 ; R_{2}=\right.$ $0.25 ; c=2$ ) the basic function is defined as:

$$
p l h=\frac{p_{i}}{1+\left(\frac{\log _{0.001} p_{i+\log _{0.25} p_{i}}}{2}\right)^{2}}
$$

Figure 1 includes visualisation on the following values and graphs:

1) The basic function of the PLH $(0.001 ; 0.25)$;

2) Scenario "Equalization in each population", in which the set of points for symmetrical configurations is linked by a series of "transit paths" consisting of points with 
successive sub-symmetrical configurations forming the boundary of "minimum cumulative hierarchy";

3) Scenario "Single leader's dominance in all populations" in which asymmetric configurations are used to model the cumulative "maximum working hierarchy";

4) Scenario "Average working hierarchy", formed by the arithmetic mean of cumulative "minimum hierarchy" and "maximum working hierarchy".

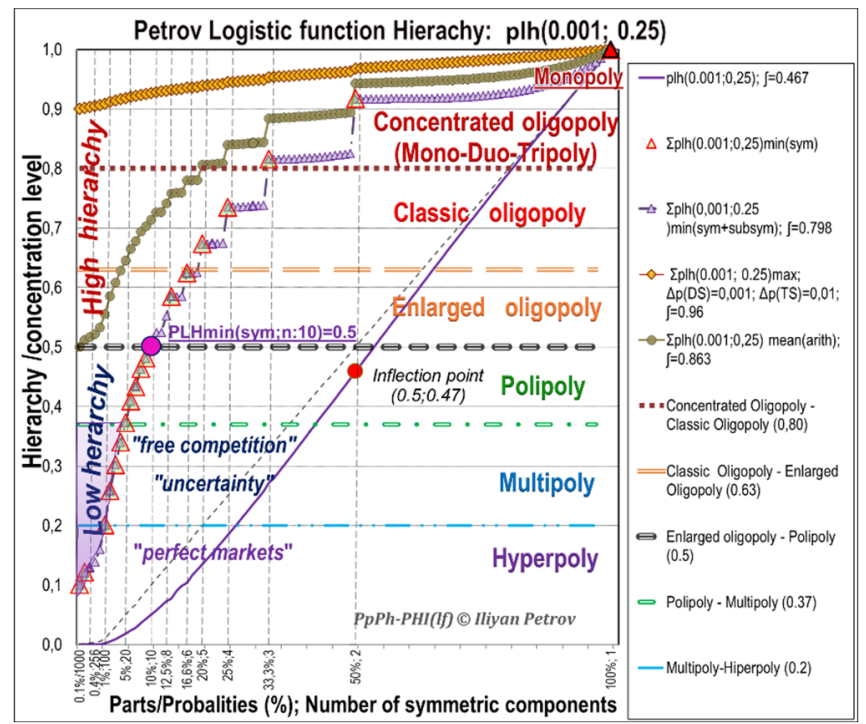

Fig. 1. Structural evolution in Petrov Logistic Hierarchy

\section{Traditional complexity indicators v/s Petrov Hierarchy}

The quality of entropy and hierarchy indicators can be assessed by comparing the integrals values of their basic functions. Graphically, this means comparing the surface (quadrature) that respective functionsin the structural space. All basic transformation functions are continuous in the interval $[0,1]$ and the determination of the values of their integrals by symbolic calculations is possible with maximum accuracy. At this level of analysis, the conclusion is obvious: the undisputed leader is the Petrov Hierarchy, followed by the Shannon Entropy, while the Herfindahl Concentration (Hierarchy) seems to be less effective tool for universal structural assessments. The symbolic calculations of basic functions integral in Maple 17 and Python 3.9 produced equivalent results, presented in Table 2.

Table 2. Integrals' Quadrature of system complexity indicators

\begin{tabular}{|l|c|}
\hline \multicolumn{1}{|c|}{ Entropy and Hierarchy Indicators (basic functions) } & $\int_{0}^{l} f\left(p_{i}\right) ;(d x=0.01)$ \\
\hline Petrov Logistic Hierarchy (PLH): equation (1) & 0.467 \\
\hline Shannon Entropy (SE): $-p_{i} \cdot \log _{2} p_{i}$ & 0.361 \\
\hline Herfihdahl Concentration (HC): $p_{i}{ }^{2}$ & 0.333 \\
\hline Shannon Entropy: $-p_{i} \cdot \ln p_{i}$ & 0.241 \\
\hline Shannon Entropy (SE): $-p_{i} \cdot \log _{10} p_{i}$ & 0.101 \\
\hline
\end{tabular}

Figure 2 presents the basic functions of the indicators of Petrov and Herfindahl Concentration (Hierarchy) and Shannon Entropy (in three logarithmic forms - with binary, 
decimal, and normal logarithm). The graphical analysis shows that the distribution of information in the integrals is also in favour of the Petrov Logistic Hierarchy (PLH).

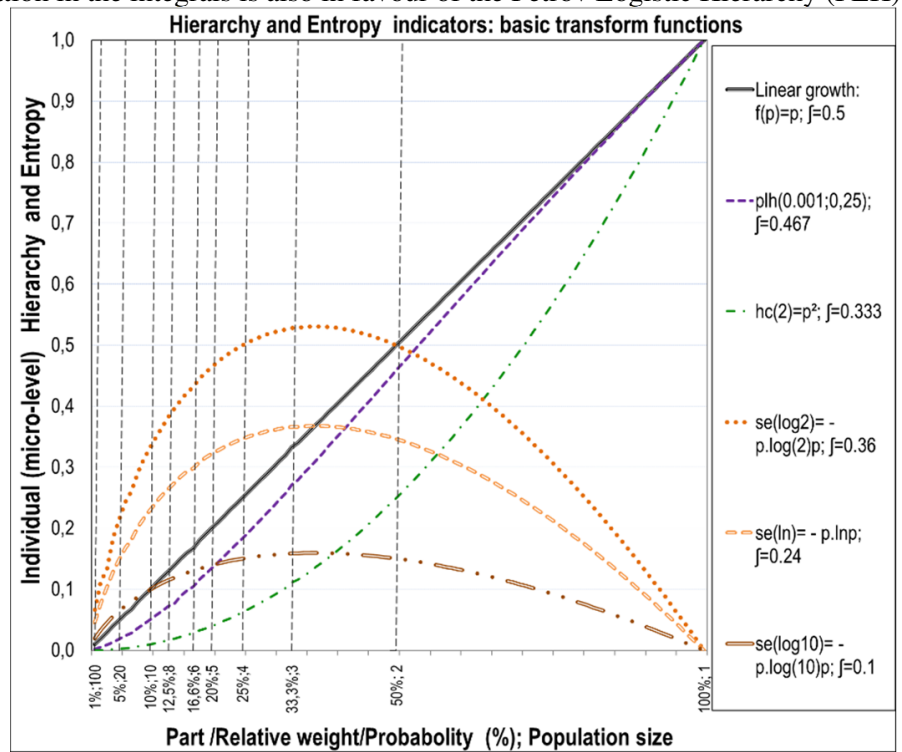

Fig. 2. Basic transform functions of Hierarchy and Entropy indicators

\section{Structural evolutions in national and world energy balances}

Sources of information and methodology. This study of energy markets and balances is based publicly available sources and up-to-date information provided in some of the most reliable and detailed annual publications in the field of energy - "IEA World Energy Outlook 2019" [9] and "BP Statistical Review of World Energy 2020" [10]. In this paper, the analysis of the structure of energy balances is made based on Petrov Logistic Hierarchy as in methodology terms it is more logical, intuitive and balanced in comparison with Shannon Entropy and Herfindahl Concentration (Hierarchy). The empiric data for all energies are recalculated (normalized) from the absolute comparable physical values in relative weights for each year, country and region.

Energy balances. The energy industry is a typical example of a complex system composed of several inter-dependent and very dynamic sub-systems, each of which employs different technologies and requires intensive and large-scale financial investments in huge industrial and infrastructure projects. Over the last five years (2015-2019), as a result of technological advances in the RES sector and climate change control policies, structural changes have become increasingly visible. During this period the hierarchy in the structure of the energy balance of the world energy calculated by the method of Petrov Logistic Hierarchy (PLH) decreased from 0.76 to 0.74 . And although traditional fossil fuels (oil, coal, and gas) still maintain their position as the three leading energy sources in most countries, their shares are gradually declining in favour of the RES sector.

This study explored the evolution of energy systems by groups of countries. The Petrov Hierarchy in variant $P L H(0.001 ; 0.25)$ allowed to obtain an objective quantitative assessment and qualitative classification of the dynamics in the structure of the energy balances since 
2014. The results of the study are summarized in Table 3 in classification phases and according the types of energy types and also on local and imported resources.

\begin{tabular}{|c|c|c|c|c|c|}
\hline Energy mix Phase: & Countries & Types of energy & 2014 & 2019 & 2020 \\
\hline \multirow{22}{*}{$\begin{array}{c}\text { Concentrated } \\
\text { Oligopoly } \\
(\mathrm{PLH}=0.8-1)\end{array}$} & \multicolumn{5}{|c|}{ Energy exporters } \\
\hline & Trinidad & $2(\mathrm{O}, \mathrm{G})$ & 0.955 & 0.95 & 0.95 \\
\hline & Turkmenistan & $2(\mathrm{O}, \mathrm{G})$ & 0.927 & 0.92 & 0.95 \\
\hline & Kuwait & $2(\mathrm{O}, \mathrm{G})$ & 0.92 & 0.92 & 092 \\
\hline & Qatar & $2(\mathrm{G}, \mathrm{O})$ & 0.93 & 0.92 & 0.92 \\
\hline & Saudi Arabia & 2 (O.G) & 0.92 & 0.91 & 0.91 \\
\hline & Iraq & $3(\mathrm{O}, \mathrm{G}, \mathrm{H})$ & 0.92 & 0.91 & 0.91 \\
\hline & Azerbaijan & $3(\mathrm{O}, \mathrm{G}, \mathrm{H})$ & 0.87 & 0.90 & 0.90 \\
\hline & Uzbekistan & $4(\mathrm{C}, \mathrm{O}, \mathrm{G}, \mathrm{H})$ & 0.91 & 0.90 & 0.90 \\
\hline & $\mathrm{UAE}$ & $4(\mathrm{O}, \mathrm{G}, \mathrm{R})$ & 0.92 & 0.88 & 0.875 \\
\hline & Venezuela & $4(\mathrm{O}, \mathrm{G}, \mathrm{H})$, & 0.82 & 0.81 & 0.83 \\
\hline & Iran & $5(\mathrm{O}, \mathrm{G}, \mathrm{H}, \mathrm{C}, \mathrm{N})$ & 0.90 & 0.89 & 0.895 \\
\hline & Egypt & $5(\mathrm{O}, \mathrm{G}, \mathrm{H}, \mathrm{C}, \mathrm{R})$ & 0.87 & 0.86 & 0.87 \\
\hline & Norway & $5(\mathrm{O}, \mathrm{G}, \mathrm{H}, \mathrm{C}, \mathrm{R})$ & 0.85 & 0.81 & 0.815 \\
\hline & Netherlands & $5(\mathrm{O}, \mathrm{G}, \mathrm{H}, \mathrm{C}, \mathrm{R})$ & 0.822 & 0.81 & 0.81 \\
\hline & \multicolumn{5}{|c|}{ Energy importers (less than $50 \%$ of own resources in EM) } \\
\hline & Singapore & $3(\mathrm{O}, \mathrm{G}, \mathrm{R})$ & 0.94 & 0.93 & 0.93 \\
\hline & Israel & $4(\mathrm{O}, \mathrm{G}, \mathrm{C}, \mathrm{R})$ & 0.82 & 0.91 & 0.91 \\
\hline & Lithuania & $5(\mathrm{O}, \mathrm{G}, \mathrm{H}, \mathrm{C}, \mathrm{R})$ & 0.92 & 0.915 & 0.91 \\
\hline & Belorussia & $5(\mathrm{O}, \mathrm{G}, \mathrm{H}, \mathrm{C}, \mathrm{R})$ & 0.91 & 0.88 & 0.85 \\
\hline & Thailand & $5(\mathrm{O}, \mathrm{G}, \mathrm{H}, \mathrm{C}, \mathrm{R})$ & 0.83 & 0.81 & 0.805 \\
\hline & Taiwan & $5(\mathrm{O}, \mathrm{G}, \mathrm{H}, \mathrm{C}, \mathrm{R})$ & 0.84 & 0,81 & 0.805 \\
\hline \multirow{34}{*}{$\begin{array}{l}\text { Classic Oligopoly } \\
(\mathrm{PLH}=0.63-0.8)\end{array}$} & \multicolumn{5}{|c|}{ Energy exporters } \\
\hline & Vietnam & $5(\mathrm{O}, \mathrm{G}, \mathrm{H}, \mathrm{C}, \mathrm{R})$ & 0.78 & 0.78 & 0.78 \\
\hline & Russia & $6(\mathrm{O}, \mathrm{G}, \mathrm{H}, \mathrm{C}, \mathrm{N}, \mathrm{R})$ & 0.78 & 0.76 & 0.765 \\
\hline & Canada & $6(\mathrm{O}, \mathrm{G}, \mathrm{H}, \mathrm{C}, \mathrm{N}, \mathrm{R})$ & 0.72 & 0.71 & 0.72 \\
\hline & \multicolumn{5}{|c|}{ Energy importers (more than $50 \%$ own resources in EM) } \\
\hline & Denmark & $5(\mathrm{O}, \mathrm{G}, \mathrm{H}, \mathrm{C}, \mathrm{R})$ & 0.76 & 0.79 & 0.785 \\
\hline & UK & $6(\mathrm{O}, \mathrm{G}, \mathrm{H}, \mathrm{C}, \mathrm{N}, \mathrm{R})$ & 0.77 & 0,76 & 0.76 \\
\hline & USA & $6(\mathrm{O}, \mathrm{G}, \mathrm{H}, \mathrm{C}, \mathrm{N}, \mathrm{R})$ & 0.74 & 0.73 & 0.735 \\
\hline & Brazil & $6(\mathrm{O}, \mathrm{G}, \mathrm{H}, \mathrm{C}, \mathrm{N}, \mathrm{R})$ & 0.78 & 0.72 & 0.73 \\
\hline & France & $6(\mathrm{O}, \mathrm{G}, \mathrm{H}, \mathrm{C}, \mathrm{N}, \mathrm{R})$ & 0.75 & 0.72 & 0.72 \\
\hline & Romania & $6(\mathrm{O}, \mathrm{G}, \mathrm{H}, \mathrm{C}, \mathrm{N}, \mathrm{R})$ & 0.72 & 0.68 & 0.675 \\
\hline & Bulgaria & $6(\mathrm{O}, \mathrm{G}, \mathrm{H}, \mathrm{C}, \mathrm{N}, \mathrm{R})$ & 0.71 & 0.68 & 0.685 \\
\hline & Finland & $6(\mathrm{O}, \mathrm{G}, \mathrm{H}, \mathrm{C}, \mathrm{N}, \mathrm{R})$ & 0.67 & 0.66 & 0.655 \\
\hline & \multicolumn{5}{|c|}{ Energy importers (less than $50 \%$ of own resources in EM) } \\
\hline & Ireland & $5(\mathrm{O}, \mathrm{G}, \mathrm{H}, \mathrm{C}, \mathrm{R})$ & 0.82 & 0.79 & 0.785 \\
\hline & Greece & $5(\mathrm{O}, \mathrm{G}, \mathrm{H}, \mathrm{C}, \mathrm{R})$ & 0.82 & 0.78 & 0.78 \\
\hline & Poland & $5(\mathrm{O}, \mathrm{G}, \mathrm{H}, \mathrm{C}, \mathrm{R})$ & 0.82 & 0.78 & 0.78 \\
\hline & Italy & $5(\mathrm{O}, \mathrm{G}, \mathrm{H}, \mathrm{C}, \mathrm{R})$ & 0.79 & 0.77 & 0.775 \\
\hline & Turkey & $5(\mathrm{O}, \mathrm{G}, \mathrm{H}, \mathrm{C}, \mathrm{R})$ & 0.745 & 0.71 & 0.70 \\
\hline & Austria & $5(\mathrm{O}, \mathrm{G}, \mathrm{H}, \mathrm{C}, \mathrm{R})$ & 0.74 & 0.71 & 0.71 \\
\hline & India & $6(\mathrm{O}, \mathrm{G}, \mathrm{H}, \mathrm{C}, \mathrm{N}, \mathrm{R})$ & 0.79 & 0.80 & 0.81 \\
\hline & China & $6(\mathrm{O}, \mathrm{G}, \mathrm{H}, \mathrm{C}, \mathrm{N}, \mathrm{R})$ & 0.85 & 0.77 & 0.76 \\
\hline & South Korea & $6(\mathrm{O}, \mathrm{G}, \mathrm{H}, \mathrm{C}, \mathrm{N}, \mathrm{R})$ & 0.79 & 0.75 & 0.75 \\
\hline & Hungary & $6(\mathrm{O}, \mathrm{G}, \mathrm{H}, \mathrm{C}, \mathrm{N}, \mathrm{R})$ & 0.75 & 0.74 & 0.74 \\
\hline & Japan & $6(\mathrm{O}, \mathrm{G}, \mathrm{H}, \mathrm{C}, \mathrm{N}, \mathrm{R})$ & 0.775 & 0.73 & 0.73 \\
\hline & Spain & $6(\mathrm{O}, \mathrm{G}, \mathrm{H}, \mathrm{C}, \mathrm{N}, \mathrm{R})$ & 0.72 & 0.73 & 0.73 \\
\hline & Ukraine & $6(\mathrm{O}, \mathrm{G}, \mathrm{H}, \mathrm{C}, \mathrm{N}, \mathrm{R})$ & 0.755 & 0.73 & 0.735 \\
\hline & Germany & $6(\mathrm{O}, \mathrm{G}, \mathrm{H}, \mathrm{C}, \mathrm{N}, \mathrm{R})$ & 0.71 & 0.71 & 0.71 \\
\hline & Belgium & $6(\mathrm{O}, \mathrm{G}, \mathrm{H}, \mathrm{C}, \mathrm{N}, \mathrm{R})$ & 0.78 & 0.71 & 0.71 \\
\hline & Czech Republic & $6(\mathrm{O}, \mathrm{G}, \mathrm{H}, \mathrm{C}, \mathrm{N}, \mathrm{R})$ & 073 & 0.71 & 0.71 \\
\hline & Sweden & $6(\mathrm{O}, \mathrm{G}, \mathrm{H}, \mathrm{C}, \mathrm{N}, \mathrm{R})$ & 0.72 & 0.70 & 0.71 \\
\hline & Slovakia & $6(\mathrm{O}, \mathrm{G}, \mathrm{H}, \mathrm{C}, \mathrm{N}, \mathrm{R})$ & 0.69 & 0.68 & 0.685 \\
\hline & $\mathbf{E U}$ & $4-5-6$ & 0.75 & 0.73 & 0.73 \\
\hline & OECD & $4-5-6$ & 0.75 & 0.72 & 0.725 \\
\hline
\end{tabular}




\begin{tabular}{|c|l|l|l|l|l|}
\hline Aggregates & World & $\mathbf{2 - 3 - 4 - 5 - 6}$ & $\mathbf{0 . 7 6}$ & $\mathbf{0 . 7 4}$ & $\mathbf{0 . 7 4}$ \\
\hline
\end{tabular}

Legend: $\mathrm{C}$ - coal; $\mathrm{O}$ - oil; $\mathrm{G}$ - gas; $\mathrm{N}$ - nuclear; $\mathrm{H}$ - hydro; $\mathrm{R}$ - renewables.

In most national energy systems that use only two or three types of traditional fossil fuels, the hierarchy of energy balances is traditionally very high and is classified in the phase Concentrated Oligopoly (0.8-1), which in reality reflects the following types of structure: monopoly, duopoly or tripoly. In most of the case these structures are based on the dominance of oil and gas - in some of them, the hierarchy levels slowly decrease, but remain above the lower limit (0.8) and a transition to the phase of Classical oligopoly (0.63-0.8). In most cases, this is due to the production of one, two, or three low-cost local energy resources, which are often actively exported on international markets. These countries are forced to develop and maintain large-scale and capital intensive projects in the extracting and infrastructure sectors and this limits their possibilities for developing the sector RES.

At this stage, for oil, gas and coal-producing and exporting countries, the very high level of hierarchy in the energy balance seems not to generate problems for their energy independence and security. At the same time, the sharp changes in world energy markets and the high volatility of international prices often lead to significant reductions of foreign exchange earnings and generate critical stress and critical situations in their social, financial, and economic systems. Particularly sensitive in this regard are Venezuela, Russia, Nigeria, Algeria, Egypt, Iran, Iraq, and other countries. At the same time, S. Arabia, Qatar, Kuwait, Oman, and the UAE, in which hydrocarbons are extracted at very low costs have accumulated significant gold and foreign exchange reserves compared to their gross domestic products and social budgets, and, subsequently are significantly less exposed to market risks. A different trend is observed in countries that use more than four types of energy but cannot achieve full or significant energy independence at the expense of their own resources. Investments in renewable energies are particularly active in countries where local traditional energy sources account for less than $50 \%$ of energy consumption. The level of hierarchy of their energy balances is steadily declining, but remains in the range of the Classical oligopoly phase (0.63-0.8) and only very few of them (Finland, Sweden) are approaching the phase of Enlarged Oligopoly (0.5-0.63).

In all countries, the yearly structural changes have an evolutionary character and are expressed within apparently very limited deviation of hierarchy values - about \pm 0.0025 0.005 on yearly basis. In energy exporting countries and big economies (USA, Japan, Germany, UK, Italy, Russia) the EM structures are more static than in smaller countries (Belgium, Greece, Romania, Bulgaria). However, the RES begin to play a more important role in the energy importing countries. In this respect, the structures of the energy mix of China, Brazil, South Korea, Turkey noticeably evolved since 2014 and contributed to the evolution in the EM structure of the World. The economies of developed countries have traditionally more diversified economies with a significant share of the services sector, in which electricity consumption is significant. As a result, at this stage, the investments in renewable energy sources are concentrated in the production of electricity from large photovoltaic and wind farms and, recently, from micro mezzo local capacities at the level of households and companies.

\section{Energy balances under COVID-19}

In the EU the main factors for diversification of the energy balance structure are the environmental policies and the active stimulation of investments in the field of RES. Unfortunately, not all RES have reached the required level of technological maturity and economic efficiency. On the positive side, the direct production of electricity by RES is becoming more dynamic and more efficient [11]. At the same time, the highly anticipated technologies for the production and use of hydrogen in transport and many industrial sectors 
need further development $[12,13]$. The EU's ambitions to reduce carbon emissions within the so-called "Green Deal" of $50 \%$ by 2030 and up to $0 \%$ by 2050 are not yet supported by clear programs and plans. This can lead to significant shocks in the coal and nuclear energy sectors in some countries (Germany, France, Bulgaria, Poland, the Czech Republic, Slovakia, and other countries), where these industries traditionally represent a significant share of the energy system [14]. Despite the ambitious political declarations, the unfavourable development of the COVID-19 pandemic and the economic crisis of 2020-21 adds further uncertainty in the plans for accelerated decommissioning of coal and nuclear power plants [15] and efficient development of the RES sector. Under conditions of COVID-19 and economic crisis, the energy sector is stagnating on World basis, with a substantial decrease in energy consumption in several industry sector like transport, construction, tourism, recreation. In most developed countries, due to the containment measures on social mobility this trend is partially mitigated by a higher electricity consumption on the level of households related to the new formats of home working and distance education. In this situation, the lower utilisation of fossil fuels was compensated by higher utilisation of RES. Unfortunately, the main RES (photovoltaics and wind farms) that depend on natural factors are not flexibly scalable and available with constant capacity. A major challenge for many countries and regions in the future will be the matching of decentralized consumption with the ambitions of close major power plants based on coal. As a result, the decrease of hierarchy of national balance was not as dynamic as expected.

Taking into account the objective lack of financial resource in big and small countries, we may expect that economic recovery will have to rely on the most accessible and locally available fossils - oil in the USA; coal in China, India, Poland, South Africa; oil and gas in OPEC and other exporting counties. In this situation, the EU is facing increasing pressure to balance between climate control and competition policies. Important changes can be expected as a result of completion of major nuclear power plants or infrastructure projects which are already under construction in a limited number of counties such as Belorussia, Finland, Hungary, Turkey, while in other countries (Japan, Bulgaria, Czech Republic) the prospective of similar projects are still under discussion.

\section{Conclusions and further research}

The results of the research show that in the theoretical aspect the approach of Petrov Hierarchy offers effective methods and tools for analysis of the dynamic systems and processes in the energy sector. The analysis of the development of energy balances in the period 2011-2019 proves the still insufficient technological development in the field of RES. In this sense, in the foreseeable future, world and national energy balances are not expected to reach the notion of a "perfect structure" and move to the "polypoly" phase with a hierarchy level below 0.5 by the method of the Petrov Hierarchy.

Of particular interest for future research are the analysis and forecasting of the structure of the RES sector. On the one hand, in the generalized statistics all types of new RES (photovoltaics, wind generators, solar heat generators, biotechnologies, hydrogen, etc.) are traditionally summarized in one group. On the other hand, the prospects for their development differ significantly. In the near future, when the share of some types of RES will reach $4-5 \%$, it would be appropriate to divide them into separate items in a timely and clear manner and to start considering them as separate items in the energy balances. In this respect the analysis of energy security and diversification in the "E-6" format (i.e. based on six types of energy) would appear over-simplified and misleading. Such a format would reflect an incomplete picture of the real distribution and prospects for the development of production and consumption in the energy sector by countries and regions. It is possible, for example, to present the existing types of RES as 10 separate items (RES-10): 1) hydro- 
electricity; 2) photovoltaic electricity; 3) wind electricity; 4) solar heating (heat pumps); 5) geothermal energy for heating or cooling; 6) biomass; 7) biogas; 8) biofuel; 9) "green" hydrogen (electrolysis of water through RES); 10) "blue" hydrogen (pyrolysis of natural gas). As a result, the number of energy types increases from "6" to "14" (E-14).

Another promising direction is to explore the structural evolution of energy markets and balances not only in physical but also in economic indicators, reflecting the cost and prices of different energy sources. Such an approach may unveil some privileges for projects related to traditional energy sources or accelerated introduction of RES at unreasonably high prices which could lead to unfair competition and economic unavailability of energy in many industries and regions. An objective analysis will be particularly important in the EU for attaining not only effectively but also efficiently the targets for low carbon emissions and not to the detriment of economic competitiveness.

This research is supported by the Bulgarian FNI fund through the project "Modeling and Research of Intelligent Educational Systems and Sensor Networks (ISOSeM)", contract KP-06-H47/4 from 26.11.2020.

\section{References}

1. C. Shannon, W. Weaver., The Bell Sys. Tech. J. 27, 379-423 (1948)

2. A. Renyi, On measures of information and entropy., Proceedings of the fourth Berkeley Symposium on Mathematics, Statistics and Probability 547-561 (1961)

3. O. Herfindahl, Concentration in the U.S. Steel Industry (dissertation, Colum. Univ., 1950)

4. E.H. Simpson, J. Nature 163 (4148), 688 (1949)

5. E. Harrington, The desirability function. Ind. Qual. Contr. 21(10), 494-498 (1965)

6. I.I. Petrov, J. Econ. Altern. 1, 5-15 (2016)

7. Guidelines on the assessment of horizontal mergers under the Council Regulation on the control of concentrations between undertakings (2004/C 31/03) /Section "HHI levels" paragraph 19-20; Off. J. of EU (05.02.2004) https://eur-lex.europa.eu/legalcontent/EN/TXT/PDF/?uri=CELEX:52004XC0205(02)

8. I.I. Petrov, I.I., Structural Evolution of World and European energy markets and the development of gas pipeline networks in South-East Europe with participation (Ph.D. dissertation, Russian State University for oil and gas, Moscow, 2015).

9. BP Stat. Rev. of W. En.: - Statistical Review of World Energy - all data, 1965-2019 (2020)

10. IEA World Energy Outlook - 2020, Int. En. Outlook (2020)

11. Agora Energie ${ }^{2}$ wende (2020): "The European Power Sector in 2019: Up-to-Date

Analysis on the Electricity Transition", https://www.agora-

energiewende.de/fileadmin2/Projekte/2019/Jahresauswertung_EU_2019/172_A-EW_EU-

Annual-Report-2019_Web.pdf (2020)

12. Dickel. R., Blue hydrogen as an enabler of green hydrogen: the case of Germany (Oxford Institute for Energy Studies, ISBN978-1-78467-159-4, (2020)

13. Stahl Business Association (2020): National hydrogen strategy in delay, https://www.stahl-online.de/index.php/nationale-wasserstoffstrategie-in-verzug/

(17.0.3.2020)

14. German Coal Commission: "Growth, Structural Change and Jobs Commission: Final report"; https: //www.bmwi.de/Redaktion/DE/Downloads/A/abschlussbericht-kommissionwachstum-strukturwandel-und-beschaeftigung.pdf?_blob=publicationFile ((2019)

\footnotetext{
${ }^{2}$ Corresponding author: petrovindex@gmail.com
} 
15. Energate Messenger (2020): "Corona shakes up coal phase-out schedule”, 6 April 2021 https://www.energate-messenger.ch/news/201586/corona-bringt-zeitplan-fuerkohleausstieg-ins-wanken?media=print 